\title{
Multicultural Aspects of Palliative Care (Original Research)
}

\section{A. Dobsonyova (Andrea Dobsonyova)1, M. Jankechova (Monika Jankechova)², M. Frankova (Maria Frankova) ${ }^{3}$}

${ }^{1}$ St. Elizabeth University of Health and Social Sciences Bratislava, doctorate program, SK

${ }^{2}$ St. Ladislaus Faculty of Health and Social Sciences, St. Elizabeth University of Health and Social Sciences Bratislava, SK

${ }^{3}$ Children's University Hospital, Bratislava, SK

\section{E-mail address:}

andobs@centrum.sk

\section{Reprint address:}

Andrea Dobsonyova

Lastovicia 5

94001 Nove Zamky

SK

Suource: Clinical Social Work and Health Intervention

Volume: 8

Issue: 4

Pages: $35-43$

Cited references: 8

\section{Reviewers:}

George Benca

House of family St. Max Kolbe, Children's Hospital Clinic Phnom Penh, KH

Victor Namulanda Wanjala

Catholic University of Eastern Africa, Nairobi, KE

\section{Key words:}

Multiculturality. Cultural Needs. Terminal Nursing Care. Dying. Religion.

\section{Publisher:}

International Society of Applied Preventive Medicine i-gap

CSWHI 2017; 8(4): 35 - 43; DOI 10.22359/cswhi_8_4_04 C 2017 Clinical Social Work and Health Intervention

\section{Abstract:}

Aim: This paper deals with terminal care from the aspect of multiculturality. Our aim was to assess the satisfaction of the culture-specific needs of dying patients by Nurses in selected health care institutions. 
Methodology: In the research, we used a quantitative method for data collection and processing. We constructed and used a questionnaire, which was voluntary and anonymous.

Sample: The target group of the research consisted of 175 Nurses working in health care institutions in Slovakia, Germany and Sweden.

Results: We processed the collected data quantitatively, and are presenting them in their absolute and relative frequency. We processed the results of the research statistically by the Chi-square goodness of fit test, the Mann-Whitney $U$ test, and the Shapiro-Wilk test of normality. We arranged the results into tables and charts.

Conclusion: The contribution of the paper is to call attention to the subject matter and make the provision of nursing care to patients of different cultures more efficient.

\section{Introduction}

Multiculturality with respect to health is a new focus of the attention of the society, of the health care system, and of health professionals. It is becoming an increasingly large reality not only for patients but also for health care providers. One of the most important aspects of caring for a dying person is to provide her/him with qualified help, so that the last moments of life could be spent in accordance with their own social and cultural background and religious beliefs since, in the terminal stage of an illness, besides a need to cope with pain, spiritual needs are almost always in the foreground,

In our research, we sought to assess whether Nurses are aware of the specifics of the various cultures, and to what extent they respect the spiritual needs and specific rituals of patients of varying cultures. Also, we sought to assess to what extent the conditions for providing culture-specific care are ensured in health care institutions.

\section{Method}

We used a quantitative method of data collection. We constructed a questionnaire, which was voluntary and anonymous. The questionnaire was aimed at Nurses and their attitudes to satisfying and respecting the culture-specific needs of patients of other cultures. Before carrying out the research, we performed a pilot testing of the questionnaire, and a preliminary research. The research took place from September 2016 to June 2017. The selection of the health care institutions, as well as of the respondents, was intentional. The target group of the research consisted of Nurses working in health care institutions in Slovakia, Germany, and Sweden. The total number of the respondents was 175 . We gained approval for carrying out the research in all the respective health care institutions. We processed the collected data quantitatively, and presented them in tables and charts, using Microsoft Excel. We presented the data in their absolute and relative frequency. For cardinal variables, we presented also the values of the arithmetic mean and the respective standard deviation, the values of the median, of the mode, and the minimum and maximum values. 


\section{We used the following statistical tests}

Chi-square goodness of fit test - used for categorical variables for a comparison of the observed and the expected frequencies;

Mann-Whitney $U$ test - non-parametric test for comparing the differences between two independent groups, provided that the dependent variable is at least ordinal, or, if it is cardinal, then not normally distributed, Shapiro-Wilk test of normality - for testing the distribution of the normality of the data.

The revealed statistical significance of the results was compared in relation to a 0.05 significance level. In the case of statistically significant results, we determined the substantive significance as well, expressed by effect size $r$ and effect size w. Effect size $r$ was calculated by the Mann-Whitney $U$ test with the formula, with $\mathrm{Z}=\mathrm{z}$-score (result from the Mann-Whitney $U$ test), and $\mathrm{N}=$ size of the investigation set (total). Effect size w was calculated by the Chi-square goodness of fit test with the formula, with $\chi^{2}$ $=$ the value of the Chi-square, and $\mathrm{N}=$ size of the investigation set. The interpretation of the effect size was governed by classic recommendations: small effect size ca. 0.1, medium effect size ca. 0.3 , and large effect size above 0.5 .

\section{The Results of the Research}

After collecting the data through the questionnaire, we analyzed them.

We assessed whether, when admitting a patient, the Nurses surveyed what her/his religion was. In the said item, $78.90 \%$ of the Nurses stated that they did not enquire what the patient's religion was when admitting; $21.10 \%$ of the Nurses said they enquired what the patient's religion was.

We assessed whether the Nurses respected the use of alternative forms of pain management, such as herbs; tea; acupuncture; music therapy; incense sticks; or prayers.
In the said item, $44.00 \%$ of the Nurses stated that they respected the use of alternative forms of pain management $13.70 \%$ said they did not respect the use of alternative forms of pain management.

We assessed whether the Nurses respected the specific rituals connected with dying and death, such as ritual objects; prayers; calling a cleric to the dying person; incense sticks; chants or songs. In the said item, $73.70 \%$ of the Nurses stated that they respected the specific rituals connected with dying and death; $5.70 \%$ of the Nurses said they did not respect the specific rituals connected with dying and death.

We assessed whether the Nurses respected the use of religious items, such as prayer books; pictures of saints; prayer rugs; rosaries; or other sacred items of a given culture. In the said item, $78.30 \%$ of the Nurses stated that they respected the use of religious items, and $1.10 \%$ of the Nurses said they did not respect the use of religious items.

\section{Interpretation of the Results and Discussion}

We analyzed the depicted data statistically, and verified the hypotheses we had formed.

In Hypothesis 1, we assumed that the Nurses respected the needs of patients with regard to their different culture.

129 Nurses (73.70\%) respect the needs of patients with regard to their different culture, and 46 Nurses (26.30\%) do not respect their needs. The findings are presented in Chart A. 
Chart A: Respecting vs. not respecting the needs of patients with regard to their different culture.

\section{Hypothesis 1}

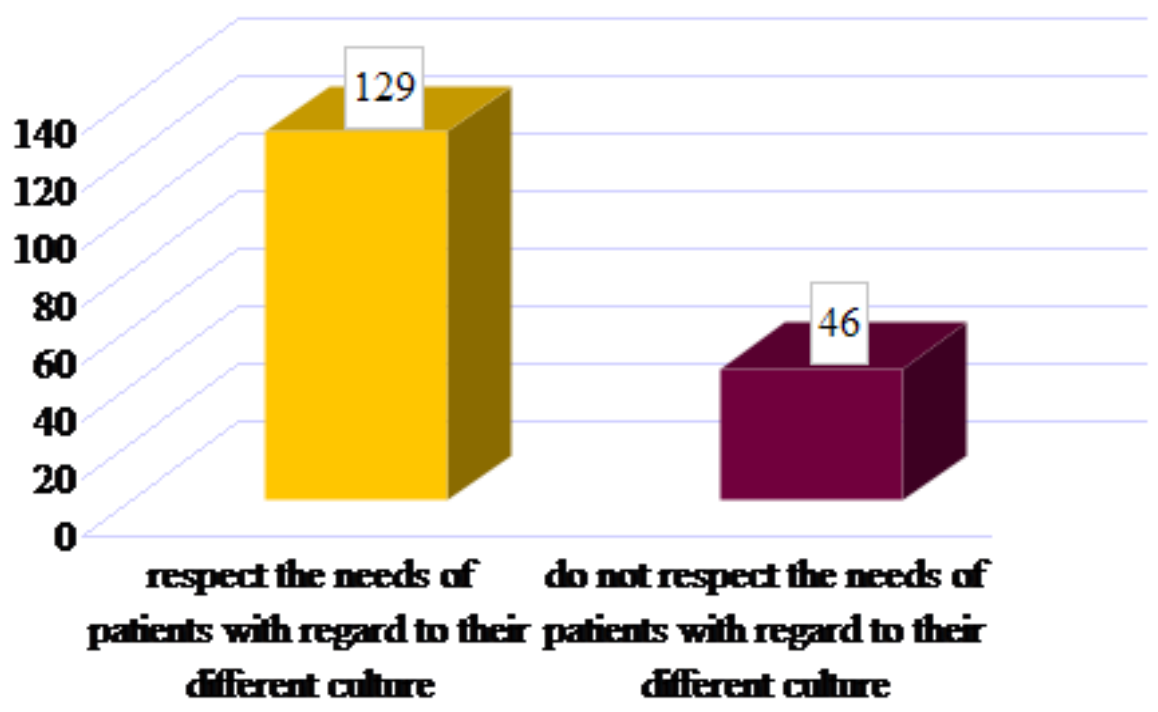

We verified the result statistically, using the Chi-square goodness of fit test, whose value equaled 39.366 at 1 degree of freedom. The value of statistical significance was lower than the value of 0.05 (Table A1). There is a statistically significant difference in the Nurses' responses with a medium effect size. More than $70.00 \%$ of the Nurses respect the needs of patients with regard to their different culture.

In a research conducted in 2013, Nurses stated a need to take into account and respect the cultural differences in caring for patients, although they admitted that few of them really did so in practice. In spite of this attitude, the Nurses felt that they were providing adequate and high-quality care to the patients (Franková, 2017). Anita Berlin (2010) presents different attitudes of the Nurses in her Swedish study, where the majority of the Nurses express their fears of failing professionally for not having adequate knowledge of the cultures they come into contact with.

A research conducted by a team of American authors in a Californian institution of long-term care confirms the significance of satisfying the needs of patients in the terminal stage of their disease. The research focused on severely ill, dying patients. The aim was to analyse to what extent their needs are met. The result was a finding that the patients' dignity was compromised especially by the inability to comply with rituals and by not respecting their wishes (Periyakoil et al., 2013).

Table A1: Comparison of respecting vs. not respecting the needs of patients with regard to their different culture.

\begin{tabular}{|l|l|}
\hline Chi-square & 39.366 \\
\hline degrees of freedom & 1 \\
\hline statistical significance & 0.000 \\
\hline effect size W & 0.474 \\
\hline
\end{tabular}


Conclusion: Based on the results of the statistical analyzes, we found that more than $70 \%$ of Nurses respected the needs of patients with regard to their different culture $\left(\chi^{2}(1)=39.366 ; p<0.05\right)$. Hypothesis 1 was confirmed by the research we conducted.

In hypothesis 2, we assumed that the Nurses respected the specific rituals of patients of other cultures. We found that 108 Nurses $(61.70 \%)$ respected the specific rituals of patients of other cultures, and 67 Nurses $(38.30 \%)$ did not respect them (at least one response to the 3 questions was negative). We present the findings in Chart B. with a low effect size. More than $60.00 \%$ of the Nurses respect the specific rituals of patients of other cultures.

A common feature of all religions is the use of symbols connected to religious rites. Chants; hymns; prayers; services; fasts are all considered to be ritual acts (Davie, 2013). In her research conducted in Bosnia and Herzegovina, Aida Bešić (2012) surveyed the respondents' attitudes to respecting the religious and cultural needs of patients. Based on the Nurses' responses, she established that the Nurses were ready to meet the patients' specific needs with respect to using religious items and rituals connected

Chart B: Respecting vs. not respecting the specific rituals of patients of other cultures.

\section{Hypothesis 2}

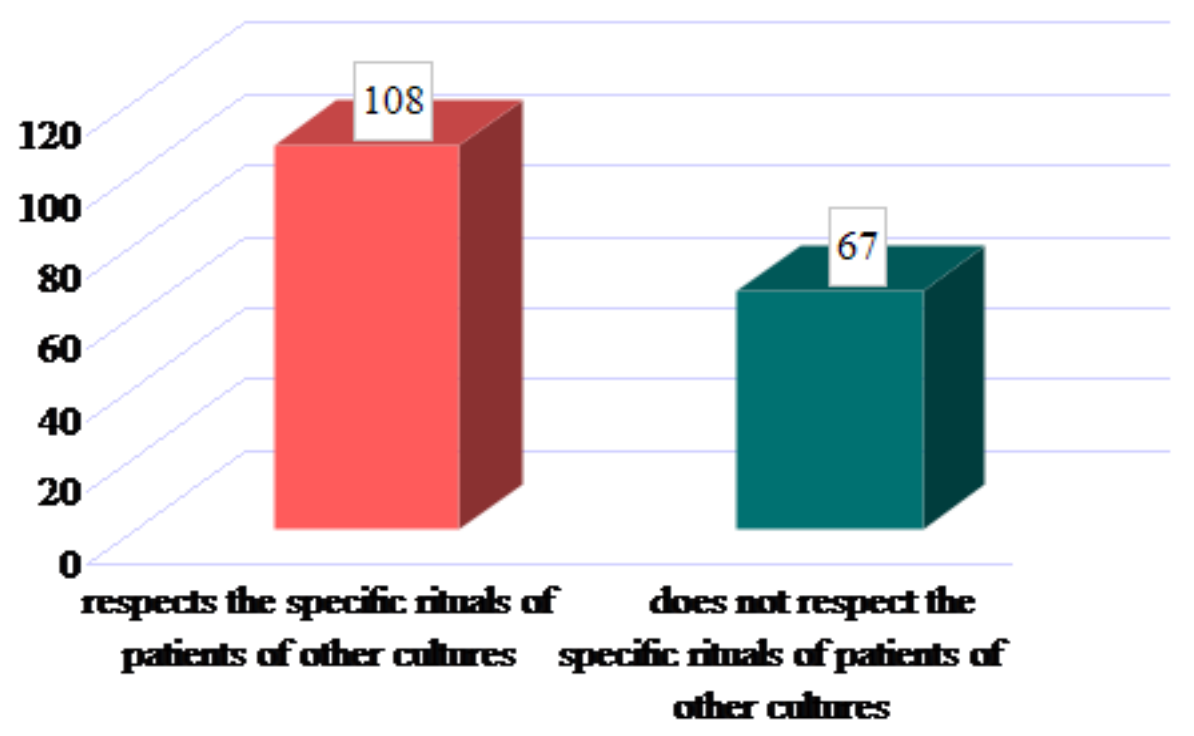

We used the Chi-square goodness of fit test to find out the statistical difference. Its value equalled 9.606 at 1 degree of freedom. The statistical significance was lower than the value of 0.05 (Table B1), so we conclude that there is a statistically significant difference between the Nurses' responses with dying and death. A research conducted in the Czech Republic (2008) also arrived at the same conclusion, with $85.47 \%$ of the Nurses considering it important to be informed about the customs, needs and values of other ethnic and religious groups (Franková, 2017). 
Table B1: Comparison of respecting vs. not respecting the specific rituals of patients of other cultures.

\begin{tabular}{|l|l|}
\hline Chi-square & 9.606 \\
\hline degrees of freedom & 1 \\
\hline statistical significance & 0.002 \\
\hline effect size W & 0.02 \\
\hline
\end{tabular}

Conclusion: Based on the results $\left(\chi^{2}(1)\right.$ $=9.606 ; \mathrm{p}<0.05)$, we conclude that more than $60.00 \%$ of Nurses respect the specific rituals of patients of other cultures, and confirm Hypothesis 2.

In Hypothesis 3, we assumed that the Nurses were familiar with the specifics of various cultures.

The results we gained by the investigation, with the use of questionnaires meant to verify the given hypothesis, show that more than half of the answers given by Nurses were correct in the case of 59 Nurses $(33.70 \%)$, whereas we recorded fewer than 4 of the answers correct in the case of 116 Nurses $(66.30 \%)$. We present the findings in Chart $\mathbf{C}$.
We compared these answers using the Chi-square goodness of fit test whose value equaled 18.566 at 1 degree of freedom. The resulting statistical significance was lower than 0.05 , so we may conclude that there is a statistically significant difference between the Nurses' responses with a low effect size (Table. C1).

Similar results were revealed by a study in Iran whose aim was to investigate the experience of health care professionals providing care for migrants in Mashhad. The research found inadequate knowledge in the given field, and an inability of the health care professionals to satisfy the emotional and mental needs of the patients (Amiri et al., 2016).

Table C1: Comparison of correct answers by the Nurses about the specifics of the various cultures.

\begin{tabular}{|l|l|}
\hline Chi-square & 18.566 \\
\hline degrees of freedom & 1 \\
\hline statistical significance & 0.000 \\
\hline effect size W & 0.02 \\
\hline
\end{tabular}

Chart C: Correct answers by the Nurses about the specifics of the various cultures.

\section{Hypothesis 3}

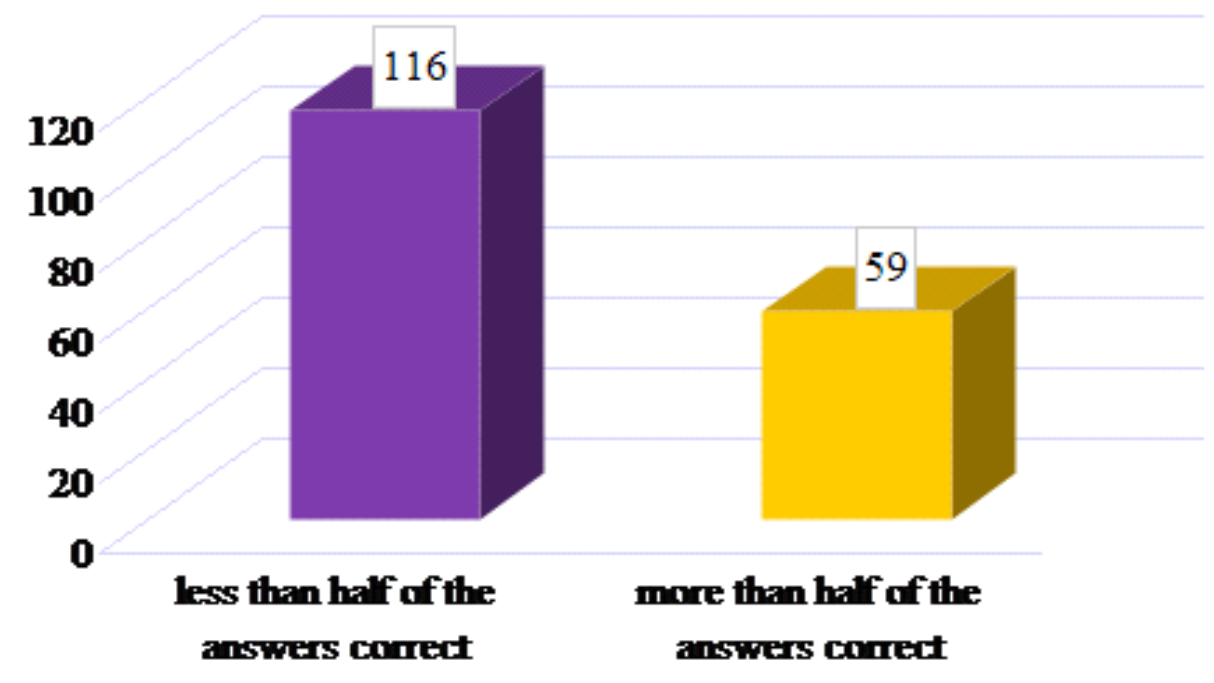


Conclusion: Based on the findings, we may establish that more than $60.00 \%$ of the Nurses are unfamiliar with the specifics of the various cultures $\left(\chi^{2}(1)=18.566 ; \mathrm{p}<\right.$ $0.05)$ and, consequently, we do not confirm Hypothesis 3 in the research we conducted.

In Hypothesis 4, we assumed that the conditions for providing culture-specific care were ensured to a greater extent in health care institutions abroad than in those in Slovakia.

We verified this hypothesis by questions regarding the possibilities to communicate with foreign-language patients; the possibility to provide food to the patients while taking into account their culture; by the question whether the health care institution has a prayer room for patients of various religions (at least for two religions); whether it is possible for the staff of the department to provide care by a female member of the staff on the patient's request.

In the said items, we coded the positive answers by the value of 1 , and the negative answers, or the "do not know" answers by the value of 0 . In this way, we got a scale from 0 to 4 , where the higher the value, the greater the extent to which the conditions for providing culture-specific care in health care institutions are met.

In Slovak health care institutions, the arithmetic mean was $\mathrm{AM}=2.7$ with a standard deviation of 0.89 and, abroad, the arithmetic mean was AM $=3.04$ with a standard deviation of 0.64 . The results are shown in Table D1 as well as in Chart D.

Table D1: Ensuring conditions for providing culture-specific care in health care institutions by country.

\begin{tabular}{|l|l|l|l|c|c|c|c|}
\hline & $\mathrm{n}$ & $\mathrm{AM}$ & $\mathrm{SD}$ & median & mode & $\min$ & $\max$ \\
\hline Nurses from Slovakia & 125 & 2.7 & 0.89 & 3 & 3 & 0 & 4 \\
\hline Nurses from abroad & 50 & 3.04 & 0.64 & 3 & 3 & 1 & 4 \\
\hline
\end{tabular}

Legend: $\mathrm{AM}$ - arithmetic mean, $\mathrm{SD}$ - standard deviation, min - minimum, max - maximum

Chart D: Ensuring conditions for providing culture-specific care in health care institutions by country (arithmetic mean).

\section{Hypothesis 4}

4

3

2

1

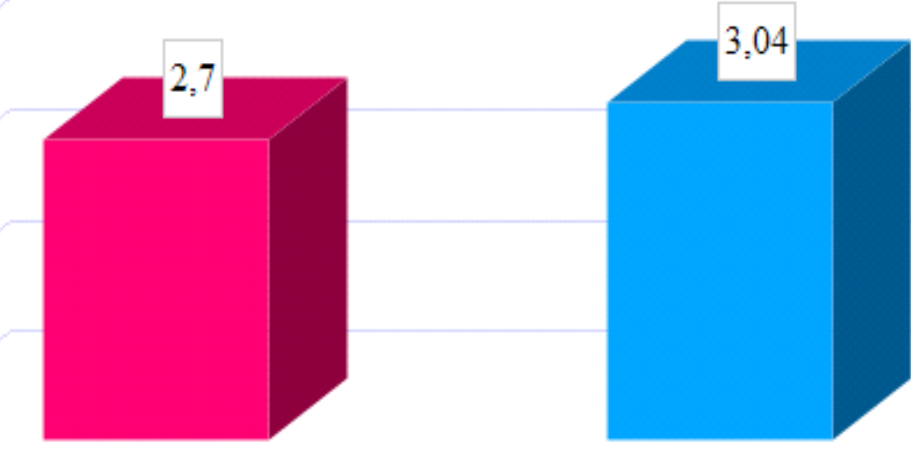

$\mathbf{0}$ 
Prior to comparing Slovak and foreign health care institutions, we verified the normality of the data distribution, which we rejected based on the results of the Shapiro-Wilk test and, therefore, we used the nonparametric Mann-Whitney $U$ test. Its value equalled 2,466.5, and the statistical significance was lower than the value of 0.05 (Table D2). There is a statistically significant difference between health care institutions in Slovakia and abroad in terms of ensuring conditions for providing culture-specific care with a low effect size. These conditions are ensured to a greater extent in foreign health care institutions (based on values of average order).

Table D2: Comparison of ensuring conditions for providing culture-specific care in health care institutions by country.

\begin{tabular}{|l|l|}
\hline $\begin{array}{l}\text { Slovakia - average order } \\
(\mathrm{n}=125)\end{array}$ & 82.73 \\
\hline $\begin{array}{l}\text { abroad - average order } \\
(\mathrm{n}=50)\end{array}$ & 101.17 \\
\hline Mann-Whitney U test & $2,466.5$ \\
\hline statistical significance & 0.017 \\
\hline effect size $\mathrm{r}$ & 0.18 \\
\hline
\end{tabular}

The results of foreign researches confirm inadequacies mainly in the field of communication.

In an American study, the authors focused on multicultural care for women of various ethnicities. The research found negative experiences of the patients in the field of communication (Wheatley et al. 2008).

Conclusion: Based on the results, we found that the conditions for providing culture-specific care are ensured to a greater extent in health care institutions abroad than in those in Slovakia $(U=2,466.5, p<0.05)$. The results of our research confirmed Hypothesis 5 .

\section{Recommendations for Practice}

Based on the analyzes of the results of the research, we arrived at a conclusion that, to achieve efficient nursing care for patients of different cultures, it is necessary to motivate the Nurses to participate in training activities on an international level, aimed at providing nursing care while respecting and meeting the culture-specific needs of patients. It is important to create training programs and training material to educate the Nurses in the field of nursing care, and of communication with patients from different cultural environments.

\section{Conclusion}

With the increasing globalization of the world, cultures, customs, and traditions are blending into a homogenized global culture. This current phenomenon has an impact also on caring for patients in the terminal stage of their illnesses. Therefore, it is important to devote attention to this phenomenon; to improve the efficiency of the provision of nursing care; and to increase the standard of the Nurses' familiarity with the topic of multicultural care.

\section{References}

1. AMIRI R, HEYDARI A, NAYERI ND, VEDADHIR A, KARESHKI H (2016) Challenges of Transcultural Caring Among Health Workers in Mashhad-Iran: A Qualitative Study. In Global Journal of Health Science. ISSN 1916-9736. 2016, Vol. 8, No. 7, p.203-211.

2. BERLIN A et al. (2010) Cultural Competence Among Swedish Child Health Nurses After Specific Training: A Randomized Trial. In Nursing and Health Sciences. ISSN 14422018, 2010, Vol. 12, No. 3, p. 381 - 391.

3. DAVIE G (2013) The sociology of Religion: A Critical Agenda. London: Sage Publications Ltd; 2 edition, 2013. p. 328. ISBN 1849205876. 
4. FRANKOVA M (2017) The relation of multiculturalism to nursing care. St. Elizabeth University of Health and Social Work. Bratislava. 2017. p. 101.

5. PERIYAKOIL VS, STEVENS M, KRAEMER H (2013) Multi-Cultural Long Term Care Nurses' Perceptions of Factors Influencing Patient Dignity at the End of Life. In Journal of the American Geriatrics Society. ISSN 0002-8614. 2013, 61(3), p. 440-446.

6. RIDOSKO J (2014) Treatment of intra-articular femur fractures. Radix, spol. s. r. o. ISBN 978-80-87573-09-9.
7. BARTOLCICOVA B (2015) Applying a massage in sports training In: Rehabilitation ISSN 0375-0922, Vol. 52, 2015, No 3, p. 176-185.

8. WHEATLEY R, KELLEY MA, PEACOCK N (2008) Women's Narratives on Quality in Prenatal Care: A Multicultural Perspective. In Qualitative Health Research. ISSN 10497323. 2008, Vol. 18, No. 11, p. 15861598. 